\title{
Parental Factors and Sexual Risk-Taking among Young People in Côte d'I voire
}

\author{
Stella B abalola ${ }^{1}$, B O lek 0 Tambashe ${ }^{2}$ and Claudia V ondrask ${ }^{1}$
}

\begin{abstract}
ABST RACT
Côte d'I voire is the country worst affected by the HIV epidemic in West A frica, and young people in this country are a particularly vulnerablegroup. This study examined the relation between parental factors and sexual risk-taking among young people using logistic regression and survival analysis methods. Three parental factors (living in the same household as the father during childhood, perceived parental disapproval of early and premarital pregnancy, and parent-child communication about sexual abstinence) were positively associated with primary sexual abstinence (defined as yet to experience sexual debut), secondary sexual abstinence (defined as sexual abstinence subsequent to sexual debut) and reduced number of sex partners. The findings suggest that parental monitoring and control are important predictors of youth sexual behaviours and underscore the need to target parents and guardians in efforts to promote responsible sexual behaviours among adolescents. It is important to promote parent-child communication about sexual issues and empower parents and guardians to communicate effectively with their children and wards about sexual issues. (A fr J R eprod H ealth 2005; 9[1]: 49-65)
\end{abstract}

\section{Résumé}

F acteurs parentaux et la prise de risque sexuel chez les jeunes gens en Côte-d'Ivoire. La Côte-d'Ivoireest le pays le plus atteint par l'épidémie du VIH en A frique de l'ouest et les jeunes gens de ce pays constituent un groupe surtout vulnérable. Cetteétude a examinéle rapport entre les facteurs parentaux et la prise de risque sexuel chez les jeunes gens à l'aide de la regression logistique et la méthode de l'analyse de survie. Trois facteurs parentaux (lefait d'habiter dans la mème maison que le père pendant l'enfance, la désapprobation parentale perçue de la grossesse précoce et la grossesse prémaritale et la communication parent-enfant concernant l'abstinence sexuelle primaire (définie commen'ayant pas encoreeu l'expérience sexuelle), l'abstinence sexuelle secondarie (définie commeune abstinence sexuelle postérieure à l'expérience sexuelle initiale) et le nombre réduit de partenaires sexuels. Les résultats démontrent que la surveillance et l'autorité des parents sont des facteurs importants qui soulignent le besoin de viser les parents et les tuteurs dans les tentatives de promouvoir des comportements sexuels responsables chez les adolescents. II est important de promouvoir la communication parent-enfant par rapport aux questions sexuelles et de capabiliser les parents et les tuteurs afin qu'ils puissent communiquer de manière effetive avec leurs enfants et leurs pupilles quant aux questions sexuelles. (R ev A fr Santé Reprod 2005; 9[1]: 49-65)

KEY WORD S: Parent, attitude, communication, sex, behaviours, C oted'I voire

1Johns H opk ins U niversity, B loomberg School of Public H ealth, C enter for $\mathrm{C}$ ommunication Programs, Baltimore, M aryland. ${ }^{2} T$ ulane U niversity, Payson C enter for International D evelopment and Technology Transfer, $N$ ew 0 rleans, L ouisiana.

Correspondence: Stella B abalola, 111 M ark et Place, Suite310, Baltimore, M aryland 21202. Te: (410) 659-6300; Fax: (410)659-6266; E-mail: sbabalol@ jhucp.org 


\section{Introduction}

A fter decades of relative peace, Côte $d^{\prime}$ Ivoire is currently experiencing one of the worst periods of political upheavals and economic downturn in its history. Inflation and rising unemployment further compound the problems of widespread insecurity and social unrest. ${ }^{1} \mathrm{E}$ fforts aimed at achieving a vibrant, peaceful and sustainable society are undermined by the rising H IV / AIDS epidemic. With an estimated national adult infection rate of $10.8 \%$, Côte d'Ivoire is the country worst affected by the HIV epidemic in West Africa. ${ }^{2}$ AIDS now ranks second among the leading causes of death in the country, and about one million of the 16 million I vorians are estimated to be living with HIV/ AIDS. Recent data on HIV prevalence indicate that youth are a particularly vulnerable group, with females being more at risk than males. According to the UN AID S estimates for 2001, between $6.7 \%$ and $10 \%$ of female youth aged $15-24$ years are seropositive compared to only $2.5-3.5 \%$ of their male counterparts. ${ }^{3}$

There is considerable evidence that many Ivorian youth engage in sexual behaviours that expose them to the risk of HIV infection. For example, the 1998 D emographic and H ealth Survey (DHS) found that the median age at first sexual intercourse was 16.5 years for males and 17.1 years for females. ${ }^{4}$ The same survey found that $56 \%$ of male and $61 \%$ of female youth had sex during the last 12 months. Multiple sexual partnership was also a relatively common practice with $49 \%$ of sexually experienced young men reporting multiple partnership during the last 12 months. ${ }^{4}$ Condom use was also very low. ${ }^{5,6}$

Premarital risky sexual behaviours are a cause for concern because they expose young people to HIV infection and they are significant predictors of sexual behaviours later in life. A number of studies have documented a correlation between premarital sexual behaviour and extramarital intercourse. For example, in their multi-country study, White et al found that in Côte
d'I voire, the odds of engaging in extramarital sex increased with the number of sexual partners before marriage and decreased with age at sexual debut.? M oreover, considering that young people represent a significant proportion of the population, efforts to curb the spread of the infection and prevent a generalised epidemic should focus on this age group as a key audience.

An appropriate approach to effective HIV prevention involves identifying and addressing the potentially modifiable factors that affect sexual behaviours and susceptibility to HIV infection among youth. There is a growing body of literature on the links between parental factors and adolescent sexual attitudes and behaviours. E xisting literature, mostly from the West, provide equivocal evidence regarding the importance of parental factors relative to other environmental influences on youth sexual risk-taking.

Some developmental researchers, reflecting the behaviour genetic school of thought, argue that much of the influence attributed to parental attitudes and behaviours might in fact be due to genetic factors. ${ }^{8-10} 0$ thers have argued that parental influence declines steadily as the child moves into late adolescence and as young people become increasingly exposed to peer influences, poverty and other environmental factors. ${ }^{11,12}$

In contrast, researchers from the socialisation theoretical perspective assert that parental factors have considerable independent influence on youth risk-taking, and that such influence remains very strong during adolescence. ${ }^{13-16} 0$ ther studies have even suggested that parental attitudes and behaviours tend to mediate the potential effects of genes or peers. ${ }^{17-19}$

Traditionally, studies examining the link between young people's sexuality and parental factors have focused on parent-child communication, parent-child closeness, parental monitoring and discipline (behavioural control), and perceived parental attitudes. 0 ther studies have examined living arrangements, with either or both parents, and parental socio-demographic 
characteristics such as level of education, income and marital status.

Parent-child communication is the parental factor most often linked to adolescent sexual attitudes and behaviours. While there is evidence that teenagers prefer to receive information about sexuality from their parents, in reality few have this privilege. ${ }^{20-24} \mathrm{~N}$ onetheless, research has documented that the quantity, frequency and timing of parent-child communication are important factors in sexual outcomes, including knowledge about sexuality and reproductive health, sexual attitudes and sexual behaviours and intentions. ${ }^{25-29}$ It is important to mention that a few studies have documented that parent-child communication is associated with greater sexual behaviour among youth. ${ }^{30} \mathrm{H}$ owever, in such studies it is not clear which comes first, the onset of sexual behaviour or the onset of parental attempts to educate adolescents about sexuality.

Strong behavioural control (parental monitoring and discipline) is increasingly recognised as an appropriate strategy to deter adolescents from engaging in risky behaviours including unsafe sexual practices. ${ }^{31,32}$ It is pertinent to note that the link between parental monitoring/ supervision and adolescent sexual behaviours may also be curvilinear. Indeed, there is evidence that too much behavioural control may have a negative effect on adolescent sexual behaviour, just as too little control does. ${ }^{33}$

A few studies have examined actual or perceived parental attitudes and behaviours and found indications that these variables are related to the sexual attitudes and behaviours of youth. In general, these studies have found that parental disapproval of teen sex is associated with late sexual debut, reduced number of sexual partners, infrequent sex and decreased teen pregnancy among youth. ${ }^{34,35}$

Studies that explored the link between living arrangements in terms of the presence of one or both parents in the same household as the adolescent have also yielded consistent results.
$\mathrm{H}$ aving been raised by both parents is associated with reduced sexual risk-taking among adolescents, while living in single-parent families is associated with increased levels of adolescent sexual risk-taking in Western countries. ${ }^{36,37}$ Similarly, a few studies have found that parental survival status and living in the same household as the father are closely linked to adolescent early sexual experimentation in African countries. ${ }^{38,39}$ I nadequate supervision and support for material needs may explain these relationships.

In sum, existing literature overwhelmingly underscores the need to address parental factors in efforts aimed at promoting safe sexual practices among adolescents. $G$ iven that few of the existing studies focus on sub-Saharan A frica, studies that examine the dynamics of parental factors in adolescent sexual risk-taking in A frican countries are clearly indicated.

\section{M ethods}

\section{Study Participants}

The data used in this paper derive from a 2001 survey among youth aged 15-24 years in three cities in Côte d'I voire, namely, A bidjan, K orhogo and Bouake. $\mathrm{H}$ aving previously determined the required sample size based on the proportion of sexually active youth that use condoms, the survey respondents were selected through a multiplestage random process that involved selecting first enumeration areas (EAs) and then households within the selected EAs. With the assistance of the Institut $\mathrm{N}$ ational de la Statistisque in Côte $d^{\prime}$ 'I voire, the research agency randomly selected a number of EAs from each study city proportionate to the population size in the city. In each of the selected EAs, all the households were listed and 40 of them randomly selected for participation in the survey. All the young people aged 15-24 years in the selected households were targeted for interview. A total of 2,681 persons (1,262 males and 1,419 females) were successfully interviewed during the survey. 
52 A frican Journal of $\mathrm{R}$ eproductive $\mathrm{H}$ ealth

\section{$M$ easures}

Criterion variables

This study examined three criterion variables:

1. A geat sex ual debut: This variable was derived from two questions in the survey tool. First, we asked if the respondents had ever had sexual intercourse, and those who had were asked to specify the age at which they had their first sexual experience.

2. Sexual abstinence during the past six months. We derived this indicator of secondary sexual abstinence from the question that asked sexually experienced respondents to specify how long ago they had sex.

3. H aving had sex with more than one sex ual partner in thepast threemonths. This variable was used to measure the prevalence of multiple sexual partnerships and was derived from the question on the number of sexual partners.

Predictor variables

A $n$ extended ideation model served as the framework for the analyses. The ideation model is an analytic psychosocial model that has its genesis in demographic literature. As a concept, ideation has been defined as ways of thinking that can be diffused through communication and social interactions..$^{39-43}$ It is a predictive model that incorporates behavioural predictors borrowed from leading psychosocial theories. The original ideation model has been extended for the purpose of our analysis to include parental factors, in addition to the individual factors. The predictor variables in the estimated Cox and logistic regression models are:

1. Parental factors: Three variables were used to measure parental influence:

Living arrangement during childhood (presence of the father in the same household as the youth).

$D$ iscussion of sexual abstinence with the father or mother during the last 12 months.
The perceived attitudes of parents regarding a pregnancy at this stage of the respondent's life.

2. Ideational variables: Five categories of ideational variables were included in the estimated models:

Perceived self-efficacy to refuse sex under specific circumstances including with someone known for a few days, with someone known for more than three months, and with someone loved truly. Perceived self-efficacy is an emotional construct.

$\square$ Self-esteem, a cognitive construct derived from the Rosenberg self-esteem scale (RSE S)..$^{44}$ The RSE S is one of the most widely used measures of selfesteem in literature. I nitially designed to measure the self-esteem of high school students in the US, the scale has been used and found appropriate across cultures. ${ }^{45-47}$ It contains five positive and five negative items reflecting perceptions about the self. The items were measured on a four-point Likert-type scale ranging from strongly disagree to strongly agree. To derive the indicator of self-esteem, the negative statements are reverse-scored so that higher scores indicate higher levels of self-esteem. The ten items have a Cronbach's alpha of 0.71 and a score for self-esteem was computed by summing the scores on the ten items. Respondents with a score above the median were considered as having high self-esteem

$\square \quad$ Perceived social support for premarital sexual abstinence, derived from 11 questions that asked the respondent to specify if specific significant others were in support of premarital sexual abstinence. Attitudes towards late sexual debut, measured through a question on the ideal timing of first sex for boys and girls. 
Those who responded that a boy or girl should wait until marriage or until at least 18 years to experience sex were scored 1 on this indicator while the others were scored 0.

Perceived sexual behaviour of friends, assessed through a question that asked if all, most, few or none of the respondent's friends were sexually active. The respondents that responded that all or most of their friends were sexually active were scored 1 while the others were scored 0.

3. Socio-demographic variables: The estimated models also contain socio-demographic predictor variables including:
Place of residence
Current school enrolment status
Religion
Alcohol consumption.

\section{A nalytical Procedures}

We used survival analysis methods, life table analysis and Cox proportional hazards method to identify the effects of parental factors on the timing of first sex. For many reasons, survival analytical techniques are the best indicated methods for event-history data that measure the length of time until the occurrence of an event such as age at first sex. First, in societies characterised by late sexual debut, the median age at first sex may be beyond the focal age group. A mong young people, data concerning sexual debut may be considerably skewed towards sexual inexperience. In this case, the use of standard bivariate or logistic regression methods to analyse current status data (in terms of whether respondents have or have not experienced sex) may result in considerably biased estimates. Second, since the phenomenon under study is the time to an event, it is possible that the event has yet to occur by the time the survey takes place. This phenomenon is known as observation censoring. $D$ ata on the age at first sex are right-censored because not all the respondents have experienced the phenomenon under study before the survey took place. The best way to analyse such data is to distinguish between which responses (age at first sex) are observed event times and which ones are censored times. In survival analysis, a variable is introduced to reflect this distinction. In the present analyses, respondents who had had sex were considered to have experienced the failure event at their age at first sex, whereas those who were yet to experience the event were censored at their current age.

U sing the K aplan-M eier life table method, we estimated the proportion surviving (that is, yet to experience first sex) at each age. ${ }^{48,49}$ In the preliminary step of the analyses, we focused on all respondents, whether married or not, to establish the overall pattern of the timing of first sex among males and females. We then used the log-rank test to assess the differences by parental factors.

To assess the net relationship between the age at first sex and parental factors while adjusting for the confounding effects of selected sociodemographic and ideational variables, we used Cox proportional hazards model. ${ }^{50}$ The Cox model is a semi-parametric model that has a unique advantage of allowing the inclusion of covariates and, therefore, makes it possible to assess the effects of a specific predictor variable while holding other predictors constant. The model is based on the assumption that changes in the levels of the predictor variables will produce proportionate changes in the hazard function, independent of time. Since the indicators for secondary sexual abstinence and multiple sexual partnerships are defined as dichotomous (indicator) variables, we used logistic regression to assess their relationships with parental factors. 
54 A frican Journal of R eproductive $H$ ealth Parental Factors and Sexual R isk-Taking among Young People in Côte d'I voire

\section{Results}

Timing of Sex ual $D$ ebut

$D$ ata show that majority of the respondents had experienced sexual debut in their teens (Table 1). There was no significant difference in the timing of first sex by gender as shown by the results of the log-rank test for equality of survival functions. The life table proportion that was yet to experience sex at age 18 was slightly over two-fifths for either gender and the median age at first sex was about 17.6 years.

In the next few paragraphs, we look at the variations in the timing of sexual debut by parental factors, starting with the bivariate relationships shown by the life table results (Table 2 ) and, subsequently, examining the results of the Cox Proportional $\mathrm{H}$ azards models.

Table 1 Proportions of those who were yet to have Sex at Ages $15\left(\mathrm{~L}_{15}\right)$ and 18 $\left(\mathrm{L}_{18}\right)$ and M edian Age at First Sex by Gender

\begin{tabular}{lcc}
\hline Life table function & M ale $(n=1262)$ & Female $(n=1419)$ \\
\hline$L_{15}$ & 0.872 & 0.930 \\
$L_{18}$ & 0.435 & 0.428 \\
Median (in years) & 17.64 & 17.660 \\
Log rank test: $\square^{2} / p$ & & $0.17 / \mathrm{ns}$ \\
\hline
\end{tabular}

Source: SF PS Y outh B aseline Survey, N ovember 2001

Table 2 Proportions of those who were yet to have Sex at Ages $15\left(I_{15}\right)$ and 18 $\left(\mathrm{I}_{18}\right)$ and M edian Age at First Sex by Parental Factors and Gender

\begin{tabular}{|c|c|c|c|c|}
\hline Variable/ function & \multicolumn{2}{|c|}{ Male $(n=1224)$} & \multicolumn{2}{|c|}{ Female $(n=1184)$} \\
\hline L ife table function & L ived with father & $\begin{array}{r}\text { D id not livewith } \\
\text { father }\end{array}$ & L ived with father & $\begin{array}{r}\text { Did not live with } \\
\text { father }\end{array}$ \\
\hline $\mathrm{L}_{15}$ & 0.878 & 0.856 & 0.939 & 0.914 \\
\hline $\mathrm{L}_{15}^{-15}$ & 0.438 & 0.428 & 0.472 & 0.349 \\
\hline Median (in years) & 17.65 & 17.62 & 17.85 & 17.38 \\
\hline \multicolumn{5}{|c|}{ (b) D iscussed sex ual abstinence with ether parent during past 12 months } \\
\hline $\mathrm{L}$ ife table function & $\mathrm{D}$ iscussed & $\mathrm{D}$ id not discuss & D iscussed & D id not discuss \\
\hline $\mathrm{L}_{15}$ & 0.840 & 0.874 & 0.961 & 0.927 \\
\hline $\mathrm{L}_{18}^{13}$ & 0.379 & 0.439 & 0.526 & 0.418 \\
\hline Median (in years) & 17.25 & 17.66 & 18.13 & 17.62 \\
\hline \multicolumn{5}{|c|}{ (c) Perceived parental disapproval of pregnancy at this stage in the life of the youth } \\
\hline $\mathrm{L}$ ife table function & Perceived & D id not perceive & Perceived & D id not perceive \\
\hline $\mathrm{L}_{15}$ & 0.880 & 0.851 & 0.940 & 0.907 \\
\hline $\mathrm{L}_{18}^{15}$ & 0.461 & 0.379 & 0.461 & 0.370 \\
\hline M edian (in years) & 17.80 & 17.32 & 17.82 & 17.36 \\
\hline
\end{tabular}

Source: SF PS Youth Baseline Survey, N ovember 2001 
$L$ ife T able A nalysis $R$ esults

M ore than two thirds $(68.4 \%)$ of the respondents lived in the same household as their father during childhood. For some unclear reasons, males $(71.3 \%)$ were more likely than females $(65.5 \%)$ to reside in the same household as their father ( $\mathrm{z}$ $=3.21, p<0.001)$. The relationship between childhood living arrangements and the timing of sexual debut differed by gender. $D$ ata on the males did not show the predicted negative relationship and observed differences were not statistically significant. In contrast, among females, living with the father during childhood was significantly associated with increased age at sexual debut (log rank test $\square^{2}=20.72, p<0.001$ ).

$D$ iscussion about sexual abstinencewith either mother or father during the previous 12 months was used as a proxy for parent-child communication about sex. Very few $(7.6 \%)$ of the respondents reported that they discussed sexual abstinence with either parent during the previous 12 months. Among males, the relationship between discussion about sex with parents and the timing of sexual debut was statistically significant (log rank test $\square^{2}=4.32$, p $<0.05$ ) but not in the expected direction. Parentchild communication about sex was associated with earlier sexual debut among boys. A mong girls, the relationship was statistically significant (log rank test $\square^{2}=10.68, p<0.001$ ) and in the expected direction. The life table median age at sexual debut was higher by about 0.5 year among girls who reported discussion about sexual abstinence with their parents.

A s expected, perceived parental disapproval of pregnancy at the current stage in the life of the youth varied by age of the respondent. While $80 \%$ of respondents aged $15-19$ years reported that a pregnancy at this stage of their lives would disappoint their parents, only $61 \%$ of those aged 20-24 years did. The data show that parental disapproval of pregnancy is strongly associated with delayed sexual debut among both male (log rank test $\square^{2}=15.6, p<0.001$ ) and female (log rank test $\square^{2}=38.3, p<0.001$ ) respondents. A frican Journal of Reproductive $\mathrm{H}$ ealth $\mathrm{V}$ ol. $9 \mathrm{~N} 0.1 \mathrm{~A}$ pril 2005
Cox Proportional $H$ azards $R$ esults

In order to assess the net relationships between parental factors and the timing of sexual debut, we estimated a set of Cox proportional hazards models that control for the confounding influences of selected socio-demographic and ideational variables. We estimated separate models for males and females and the results are provided in Table 3.

The data show that, after controlling for socio-demographic and ideational variables that have been empirically demonstrated to influence sexual activity, parental factors are strong predictors of the timing of sexual debut among females. Jointly, the parental variables contributed significantly to explain the timing of first sexual intercourse. The introduction of parental variables in Model 4 resulted in a significant increase in the explanatory power of the estimated model as the results of the log-likelihood ratio test show. Moreover, each of the parental variables was significant in predicting the timing of sexual debut. The perceived parental disapproval of a pregnancy at the present stage of the respondent's life was the most significant of the three variables. The data show that, at a given time, the female respondents who perceived parental disapproval of pregnancies and who had not yet experienced sex had a $21 \%$ decreased risk of experiencing sex compared to their peers who did not hold this perception. In addition to parental factors, other variables that were associated with delayed sexual debut among females were perceived self-efficacy to refuse sex with someone loved truly, favourable attitudes towards late sexual debut and school enrolment. In contrast, alcohol consumption and the perception that most friends are sexually active favoured early sexual experimentation.

The story was different among males in relation to the role of parental factors. The results of the log-likelihood ratio test showed that taken jointly, parental factors did not contribute meaningfully to predicting the timing of the first sex. The only parental variable that had a 
56 A frican Journal of R eproductive $H$ ealth Parental Factors and Sexual R isk-Taking among Young People in Côte d'I voire

Table 3 Results ( $\mathrm{H}$ azard Ratio) of the Cox Proportional $\mathrm{H}$ azard M odels Linking the Timing of First Sex to Selected Socio-demographic Variables, I deational Variables and Parental Factors

\begin{tabular}{|c|c|c|c|c|}
\hline \multirow[t]{2}{*}{ Explanatory variable } & \multicolumn{2}{|c|}{$\mathrm{M}$ ale $(\mathrm{n}=1224)$} & \multicolumn{2}{|c|}{ Females $(n=1184)$} \\
\hline & Model $1^{a}$ & M odel $2^{b}$ & Model $3^{a}$ & Model $4^{b}$ \\
\hline \multicolumn{5}{|l|}{ Socio-demographic and environmental variables } \\
\hline \multicolumn{5}{|l|}{ E nrolment status } \\
\hline $\mathrm{N}$ ot enrolled $(\mathrm{RC})$ & 1.00 & 1.00 & 1.00 & 1.00 \\
\hline Enrolled & 0.90 & 0.92 & $0.74 * * *$ & $0.82 *$ \\
\hline \multicolumn{5}{|l|}{ Religion } \\
\hline Christian (RC) & 1.00 & 1.00 & 1.00 & 1.00 \\
\hline Moslem & 1.14 & 1.14 & 1.00 & 1.02 \\
\hline 0 thers & 1.17 & 1.18 & 1.10 & 1.10 \\
\hline \multicolumn{5}{|l|}{ Place of residence } \\
\hline A bidjan (RC) & 1.00 & 1.00 & 1.00 & 1.00 \\
\hline Bouake & 1.03 & 1.03 & 1.03 & 1.02 \\
\hline K orhogo & 1.01 & 1.02 & 1.04 & 1.04 \\
\hline \multicolumn{5}{|l|}{ U se of alcohol } \\
\hline N ever used alcohol (RC) & 1.00 & 1.00 & 1.00 & 1.00 \\
\hline E ver used alcohol & $1.50 * * *$ & $1.49 * * *$ & $1.21 * *$ & $1.23 * *$ \\
\hline \multicolumn{5}{|l|}{ I deational variables } \\
\hline $\begin{array}{l}\text { Perceived self-efficacy to refuse sex with someone } \\
\text { known for a few days }\end{array}$ & $0.87^{\ddagger}$ & 0.89 & 1.04 & 1.03 \\
\hline $\begin{array}{l}\text { Perceived self-efficacy to refuse sex with someone } \\
\text { known for more than } 3 \text { months }\end{array}$ & $0.79 * *$ & $0.79 * *$ & $0.80 * *$ & $0.80^{* *}$ \\
\hline $\begin{array}{l}\text { Perceived self-efficacy to refuse sex with someone loved } \\
\text { truly }\end{array}$ & $0.79 * *$ & $0.79 * *$ & 0.90 & 0.90 \\
\hline $\mathrm{H}$ igh level of self-esteem & 0.99 & 0.99 & 0.99 & 0.98 \\
\hline F avourable attitudes towards late sexual debut & $0.65^{* * *}$ & $0.64 * * *$ & $0.51^{* * *}$ & $0.51^{* * *}$ \\
\hline Perception that most friends are sexually active & $2.11 * * *$ & $2.11 * * *$ & $1.31^{* * *}$ & $1.34 * * *$ \\
\hline $\begin{array}{l}\text { Perceived social support for premarital sexual } \\
\text { abstinence }\end{array}$ & 1.00 & 1.00 & $0.96^{* *}$ & 0.97 \\
\hline \multicolumn{5}{|l|}{ Parental factors } \\
\hline \multicolumn{5}{|l|}{ L iving arrangements during childhood } \\
\hline Lived with father & & 1.03 & & $0.85^{*}$ \\
\hline $\begin{array}{l}\text { D iscussed sexual abstinence with either parents during } \\
\text { last } 12 \text { months }\end{array}$ & & $1.32 *$ & & $0.79 *$ \\
\hline Perceived parental disapproval of pregnancy at this stage & & 0.93 & & $0.79 * * *$ \\
\hline Log likelihood $\square^{2}$ & $253.50 * * *$ & $258.14 * * *$ & $184.23 * * *$ & $206.39 * * *$ \\
\hline Log likelihood ratio test: $\square^{2} / p$ & $4.64 / \mathrm{ns}$ & & $2216 / 0.0$ & \\
\hline
\end{tabular}

Source: SF PS Youth B aseline Survey, Côted'I voire, N ovember 2001

aB aseline model containing socio-demographic variables and ideational variables.

bF ull model containing socio-demographic variables, ideational variables and parental factors.

***p $\square 0.001 ; * * p \square 0.01 ; * p \square 0.05$ 
Table 4 Percentage Reporting Secondary Sexual Abstinence by Parental Factors and Gender

\begin{tabular}{lcr}
\hline Parental factors & M ale & Female \\
\hline Living arrangement during childhood & 19.0 & 17.6 \\
$\quad$ Lived with the father & 20.0 & 17.1 \\
Did not live with the father & & \\
& & 21.9 \\
D iscussion of sex ual abstinence with parents during past year & 24.1 & 16.8 \\
D iscussed & 19.0 & \\
Did not discuss & & $9.1 *$ \\
Perception that a pregnancy now would disappoint parents & $21.6^{*}$ & 13.3 \\
Perceived & 14.9 & \\
Did not perceive & & \\
\hline
\end{tabular}

* Significance of difference of means between groups: $p \square 0.01$

Source: SF PS Y outh B aseline Survey, N ovember 2001

noticeable link with the timing of sexual debut was discussion about sexual abstinence with parents and, unexpectedly, the direction of the relationship was positive. This finding strengthens the suggestion made earlier that parents tend to talk to their sons about sex only after they notice signs of sexual activity among them. 0 ther strong predictors of the timing of sexual debut among males included alcohol consumption, perceived sexual behaviours of friends and attitudes towards late sexual debut. The perceived selfefficacy to refuse sex with someone known for more than three months and the perceived selfefficacy to refuse sex with someone loved were also strong predictors of the onset of sexual activity among males.

\section{Secondary Sex ual A bstinence}

In this section, we focused on sexually experienced youth and examined how parental factors are related to secondary sexual abstinence. The absence of sexual intercourse during the last six months was used as a proxy for secondary sexual abstinence. Since secondary sexual abstinence was not relevant for married youth, the analyses in this section were limited to nevermarried youth.

$O$ verall, less than onefifth (19.3\%) of sexually experienced never-married males and $17.3 \%$ of their female counterparts reported that they did not have sex during the last three months.

Variations in the prevalence of secondary sexual abstinence by parental factors are shown in Table 4. The data suggest that residence with the father during childhood makes no difference in current secondary sexual abstinence. For example, of the males who lived with their father during childhood, 19\% reported secondary sexual abstinence, compared to $20 \%$ who did not live with their father. In contrast, the prevalence of secondary abstinence is higher among respondents that reported discussion about sexual abstinence with the parents during the past year.

It is only possible to observe secondary sexual abstinence among sexually experienced youth, but our survey covered both sexually experienced and inexperienced youth. The fact that we did not have information on secondary sexual abstinence for the sexually inexperienced youth introduces a sample selection bias into our 
58 A frican Journal of R eproductive $H$ ealth Parental Factors and Sexual R isk-T aking among Young People in C ôte d'I voire

Table 5 Results of the Probit Regression of Sexual Experience on Selected Socio-demographic Variables

\begin{tabular}{|c|c|c|}
\hline Explanatory variables & Coefficient & $\mathrm{z}$ \\
\hline \multicolumn{3}{|l|}{ Enrolment status } \\
\hline N ot enrolled (RC) & 0.00 & - \\
\hline Enrolled & $-0.57^{* * *}$ & -5.18 \\
\hline \multicolumn{3}{|l|}{ L evel of education } \\
\hline None (RC) & 0.00 & - \\
\hline Primary & 0.11 & 1.13 \\
\hline Secondary or more & $0.32 *$ & 2.42 \\
\hline \multicolumn{3}{|l|}{ Religion } \\
\hline Christian (RC) & 0.00 & - \\
\hline Moslem & $0.20 *$ & 2.48 \\
\hline 0 thers & $0.34 * * *$ & 4.01 \\
\hline \multicolumn{3}{|l|}{ Place of residence } \\
\hline A bidjan (RC) & 0.00 & - \\
\hline Bouake & 0.02 & 0.31 \\
\hline Korhogo & 0.08 & 1.02 \\
\hline \multicolumn{3}{|l|}{$G$ ender } \\
\hline Female (RC) & 0.00 & - \\
\hline Male & $-0.17^{* *}$ & -2.59 \\
\hline A ge in years & $0.28 * * *$ & 20.52 \\
\hline \multicolumn{3}{|c|}{ M edia ex posure (number of media reported) } \\
\hline None (RC) & 0.00 & - \\
\hline One & -0.02 & -0.11 \\
\hline Two & 0.15 & 1.00 \\
\hline Three & $0.32 *$ & 2.10 \\
\hline Four or more & $0.64 *$ & 3.11 \\
\hline \multicolumn{3}{|l|}{ U se of alcohol } \\
\hline N ever used alcohol (RC) & 0.00 & - \\
\hline Ever used alcohol & 0.57 & 8.23 \\
\hline $\mathrm{N}$ umber of respondents & 2408 & \\
\hline Log likelihood $\square^{2}$ & 815.38 & \\
\hline Probability $>\square^{2}$ & 0.0001 & \\
\hline Percent correctly predicted & $79.15 \%$ & \\
\hline Pseudo $\mathrm{R}^{2}$ & $26.0 \%$ & \\
\hline
\end{tabular}

*** $p \square 0.001 ; * * p \square 0.01 ; * p \square 0.05$

Source: SF PS Y outh Baseline Survey, Côted'I voire M ay 2001 
Table 6 Results (Odds Ratio) of the Logistic Regression Models Assessing the Relationship between Secondary Sexual Abstinence and Parental Factors while controlling for Socio-demographic Variables, I deational Variables and Sample Selection, by Gender

\begin{tabular}{lrr}
\hline Parental factor & Male & Female \\
\hline Living arrangement during childhood & 1.00 & 1.00 \\
D id not live with the father (RC) & 1.01 & 0.96 \\
Lived with the father & & \\
D iscussion of sex ual abstinence with parents during past year & 1.00 & 1.00 \\
D id not discuss (RC) & 0.95 & 1.37 \\
D iscussed & & 1.00 \\
Perception that a pregnancy now would disappoint parents & 1.00 & 1.54 \\
D id not perceive (RC) & 1.50 & 0.33 \\
Perceived & $4.05 *$ & 735 \\
Inverse M ill's ratio & 817 & $4.04 / 0.257$ \\
N umber of observations & $3.49 / 0.322$ & \\
Log likelihood ratio testa: $\square^{2 / p}$ &
\end{tabular}

a Compared with a baseline model containing only socio-demographic and ideational variables and sample selection factor.

*p $\square 0.05$

Source: SF PS Youth Baseline Survey, N ovember 2001

Table 7 Percentage Reporting more than O ne Sexual Partner during the last Three M onths by Parental Factors and Gender

\begin{tabular}{lcc}
\hline Parental factors & Male & Female \\
\hline Living arrangement during childhood & 19.7 & 3.8 \\
$\quad$ Lived with the father & 16.6 & 5.7 \\
D id not live with the father & & \\
& & 2.6 \\
D iscussion of sex ual abstinence with parents during the past year & 12.7 & 4.7 \\
D iscussed & 19.2 & \\
Did not discuss & & 5.6 \\
Perception that a pregnancy now would disappoint parents & $13.9 * * *$ & 3.0 \\
Perceived & 27.8 & \\
Did not perceive & & \\
\hline
\end{tabular}

Significance of difference of means between groups: ***p $\square .001$

Source: SF PS Youth B aseline Survey, N ovember 2001

A frican Journal of Reproductive $\mathrm{H}$ ealth $\mathrm{V}$ ol. $9 \mathrm{~N} 0.1 \mathrm{~A}$ pril 2005 


\section{A frican Journal of $\mathrm{R}$ eproductive $\mathrm{H}$ ealth}

data, a situation that may result in inefficient estimates. To control for possible sample selection bias, we considered the youth's decision to have sex in our estimation of the linkages between parental factors and secondary sexual abstinence using the two-stage sample selection correction procedure suggested by $\mathrm{H}$ eckman. ${ }^{51}$ In the first stage of this procedure, we used probit regression to estimate sexual experience from a set of sociodemographic variables that are susceptible to influence the decision to have sex (Table5). Using the probit results, we computed the non-selection hazard (inverse M ill's ratio) for each observation. In the second stage, we included the inverse M ill's ratio along with parental factors and other explanatory variables in the logistic regression model used to estimate the odds of reporting sexual abstinence. To ensure identification of the model, alcohol consumption, a variable that strongly predicted sexual experience but was not associated with secondary sexual abstinence, was excluded from the second model.
Separate models were estimated for maleand female respondents. For each sex, we estimated two models: a baseline model and a full model. The baseline model included socio-demographic variables (place of residence, religion, education, enrolment status, age and media exposure) and ideational variables (perceived self-efficacy to refuse sex, perceived social support for sexual abstinence, self-esteem, attitudes towards late sexual debut, and perceived sexual behavior of friends). The full model included the parental factors as well. The results of the full model are summarised in Table 6.

The male data show that the estimated coefficient on the non-selection hazard was positive and significant, which would imply selection bias such that boys who were not yet sexually active were more prone to practice secondary abstinence should they become sexually active. The results of the log-likelihood ratio test indicate that parental factors are jointly insignificant in predicting secondary abstinence. $\mathrm{N}$ one of the

Table 8 Results (Odds Ratio) of the Logistic Regression Models Assessing the Relationship between M ultiple Sexual Partnerships and Parental Factors while controlling for Socio-demographic and I deational Variables, by Gender

\begin{tabular}{|c|c|c|}
\hline Parental factor & Male & Female \\
\hline \multicolumn{3}{|l|}{ L iving arrangement during childhood } \\
\hline D id not live with the father (RC) & 1.00 & 1.00 \\
\hline Lived with the father & 1.37 & 0.64 \\
\hline \multicolumn{3}{|c|}{ D iscussion of sex ual abstinence with parents during past year } \\
\hline Did not discuss (RC) & 1.00 & 1.00 \\
\hline D iscussed & 0.70 & 0.63 \\
\hline \multicolumn{3}{|c|}{ Perception that a pregnancy now would disappoint parents } \\
\hline D id not perceive (RC) & 1.00 & 1.00 \\
\hline Perceived & $0.52 * * *$ & 2.33 \\
\hline Inverse Mill's ratio & $0.06 * * *$ & 0.64 \\
\hline $\mathrm{N}$ umber of observations & 817 & 735 \\
\hline Log likelihood ratio testa: $\square^{2} / p$ & $13.88 / 0.003$ & $5.55 / \mathrm{ns}$ \\
\hline
\end{tabular}


factors had any independent link to secondary abstinence.

As for the female data, the coefficient associated with thenon-selection hazard was positive but not significant; indicating that sample selection was not present. However, similar to what the male data indicate, parental factors were jointly insignificant in predicting secondary sexual abstinence among females.

\section{M ultipleSex ual Partnerships}

In this section, the proportion that reported more than one sexual partner during the last three months was the dependant variable and was used as a proxy for the prevalence of multiple sexual partnership. The data showed that very few of the girls $(4.5 \%)$ and a noticeable proportion of the boys $(18.8 \%)$ reported more than one sexual partner during the past three months. The data further showed that adolescent males (14.0\%) were significantly less likely to report multiple sexual partnership than their older counterparts $(22.3 \%)$. In contrast, there was no difference between adolescent females $(4 \%)$ and female young adults $(5 \%)$.

Looking at the bivariate results (Table 7), we found that among females, multiple sexual partnerships did not appear to vary noticeably by any of the parental factors considered. As for males, the only parental factor that appeared to have had the expected significant relationship with multiple sexual partnerships was the perceived parental disapproval of pregnancy. The proportion of males that reported multiple sexual partnerships was more than twice as high among respondents that did not perceive parental disapproval of pregnancy than among their peers that perceived disapproval.

To assess the net relationships between parental factors and multiple sexual partnerships, we estimated various logistic regression models that corrected for sample selection as described in the previous section. We also estimated two models for each sex: a baseline model and a full model. The predictor variables in the estimated model were the same as in the previous section.

For male youth, the coefficient associated with the indicator for sample selection was significant and negative. This again shows that selectivity is an issue among males and specifically indicates that male youth that choose to be sexually inactive are less prone to multiple sexual partnerships than any randomly selected male youth. The logistic regression results showed that parental factors were jointly significant predictors of multiple sexual partnerships although the only parental variable that was individually significant was the perceived parental disapproval of pregnancy (Table 7). The data showed that males who perceived parental disapproval for pregnancy at this stage in their lives were $48 \%$ less likely than their peers to engage in multiple sexual partnerships.

A s for the female data, the selectivity variable was not significant, indicating that sampling bias was not present in the data. Furthermore, for this group, the results of the logistic regression indicated that parental factors were not of importance in predicting multiple sexual partnerships.

\section{Discussion}

This study has examined the relationships between parental factors and sexual risk-taking among young people in Côte d'I voire. The results confirm that early sexual experimentation is the norm among young people: at age 18 years only about two fifths of either sex were yet to experience sexual debut.

The data largely confirm what existing studies from developed countries have demonstrated and show that parental factors play some role in determining the sexual attitudes and behaviours of young people. In terms of the magnitude and direction of the relationships, the three parental factors considered have disparate influences on males compared to females.

For example, living in the same household as the father during childhood was strongly 
associated with delayed sexual debut among females but not among males. This finding suggests the existence of a gender-based double sexual standard among parents and points to the need to target parents with messages aimed at promoting egalitarian treatment of male and female youth in sexual matters. There is need for appropriately designed communication interventions that address gender stereotypes among parents and engage them in promoting delayed sexual debut among both male and female children.

The relationship between parent-child communication about sexual abstinence and the timing of sexual debut also differed by sex. The relationship was significant for both sexes; however, while it was negative among females it was positive among males. The finding that discussion about sexual abstinence with parents is associated with early sexual debut among males suggests that parents tend to talk to their sons about sex only after signs of sexual activity have become visible. It is also possible that parents tend to encourage their sons to engage in sexual intercourse. This finding has important programmatic implications. Appropriately designed strategic communication interventions should encourage parents to be proactive in initiating discussions about sex with their children, and in encouraging their children to delay sexual debut irrespective of the child's sex. It is particularly important to encourage and empower parents to start to communicate with their children on sexual matters while the children are still in late childhood or early teenage years, before they become sexually active. In this regard, an effective communication intervention will beonethat not only encourages and motivates parents to discuss sex with their children but actually trains them and provides them with the necessary tools to do so.

It is important to mention that in Côte $d^{\prime}$ 'I voire, as in most of the other countries in the sub-region, parent-child communication about sex is not normative. Promoting parent-child communication about sex would, therefore, involve attempts to change social norms about parental role in the sexuality education of their children. N onetheless, historical evidence has shown that while social norms are not easy to change, they are not static either. Changing the social norms about the role of parenting in adolescent sexuality education will require consistent and persistent interventions at multiple levels. Targeting individual level behaviour change alone cannot produce sustainable positive results. Effective interventions should go beyond psychosocial theories and draw on appropriate theories of structural and environmental change. In this regard, one pertinent theory is the empowerment model, which emphasises the need for empowerment at three levels: personal, organizational, and community.

The data show that after controlling for confounding factors, parental attitudes towards a pregnancy made significant difference for the timing of sexual debut among females but not among males. This finding reinforces the need for parents to be consistent in denouncing early and premarital sexual activity with equal vigour among both male and female children.

Parental factors were jointly insignificant in predicting secondary sexual abstinence. Although the data suggest that young people who perceived that their parents disapproved of premarital pregnancy were less likely to engage in frequent sexual intercourse, the relationship was only weakly significant. It is possible that when parents disapprove of early childbearing such attitude is typically not expressed strongly enough to discourage continued sexual activity among sexually experienced youth. The results of a positive deviance inquiry (PDI) conducted by JHU/CCP in Côte d'Ivoire as a prelude to the survey reported in this article show that pressure from parents is a threat to continued sexual abstinence in late teenage and young adulthood years. Indeed, the PD I results show that parents tend to encourage their late teenage and young 
adult children to become sexually active. This finding points to the need to educate parents on the threat of HIV and other STIs for youth and on methods of preventing the infection. In this way, should parents choose to encourage their children to become sexually active, they would at least beable to advice them on ways of preventing sexually transmitted infections.

Taken jointly, parental factors were important in determining the practice of multiple sexual partnerships among male youth but not among their female counterparts. The absence of astrong linkage between parental factors and sexual behaviours among youth may be spurious and due to the fact that very few female respondents have had more than one sexual partner during the past three months. Among males, the only parental factor that strongly predicted multiple sexual partnerships among youth was perceived parental attitude towards early childbearing. Indeed, parental disapproval of early childbearing was a strong factor that appeared to discourage multiple sexual partnerships among male youth. This finding underscores the need to empower and encourage parents to continue providing positive rolemodels and guidance to their sexually active children. Parents need to understand that their attitudes and behaviours matter for the sexual attitudes and behaviours of their children. In general, appropriately designed communication programmes should encourage parents to be clear and unequivocal in making their values and beliefs about the timing of sexual debut, frequency of sexual intercourse and the number of sexual partners known to their children.

Finally, while the data have clearly demonstrated that parental factors were strongly associated with the sexual behaviours of young people, the cross-sectional nature of the data makes it impossible to ascertain causation. Considering that parental attitudes and sexual behaviours of young people are choice variables, the observed relationships may be due to the effects of unobserved factors that influence both

A frican Journal of Reproductive $\mathrm{H}$ ealth $\mathrm{V}$ ol. $9 \mathrm{~N} 0.1 \mathrm{~A}$ pril 2005 sets of variables. In other words, the parental factors considered in this paper (especially parental disapproval of pregnancy and discussion about abstinence) are probably endogenous to the sexual behaviours of young people. It is also possible that the observed relationships are due to reverse causation - sexual behaviours of young people prompting remedial parental attitudes and not vice versa. Cross-sectional data do not allow us to ascertain the extent to which endogeneity bias and reverse causation were relevant among the study population. L ongitudinal data are necessary to understand the sequence of events in the life of a young person and ascertain the direction of causality between parental factors and the sexual behaviours of young people. Further research along this line is therefore indicated.

\section{Acknowledgments}

Tulane U niversity and the Johns Hopkins U niversity Center for Communication Programs (JHU/CCP) provided technical assistance to the I vorian É coleN ationale Supérieure de Statistique et d'É conomie A ppliquée (E N SE A) in the design and implementation of the survey. The survey was conducted to provide baseline indicators for a youth sexuality project being implemented by the regional project, Santé F amiliale et P révention du SIDA (SFPS). Funding for the survey came from the U nited States A gency for I nternational D evelopment (USAID).

\section{References}

1. Central IntelligenceAgency $(\mathrm{ClA}) . \mathrm{ClA}$ - TheWorld Factbook - Côte d'I voire. http:/ / www.cia.gov/ cia/ publications/ factbook/ geos/ iv.html

2. UNAIDS. The Report on the G lobal HIV/AIDS Epidemic - 2002. http:// www.unaids.org/ barcelona/ presskit/ barcelona\% 20report/ contents.html

3. UNAIDS/ UNICEF/ WHO. Young people and HIV/ AIDS 2002. http:/ / www.unaids.org/ html/pub/topics/ young-people/ youngpeoplehivaids_en_pdf.pdf 
64 A frican Journal of $R$ eproductive $H$ ealth

4. Institut $\mathrm{N}$ ational de la Statistique/ $\mathrm{M}$ acro Inc (IN S/ M acro). E nquête D émographiqueet deSantéen Côte d'I voire (E D SCI-II), 1998-1999. Calverton: Macro Inc., 2001.

5. Zanou B, N yankawindemera A, Toto JP and $K$ osonou $K$. Enquête de surveillance de comportements relatifs aux MST / SIDA en Côte d'I voire (BSS 1998). Rapport d'analyse des données del'enquête auprès des jeunes. A bidjan: EN SEA, 1999.

6. Yelibi S, Valenti P, Volpe C, Caprara A, D edy S and Tape G. Socio-cultural aspects of AID $S$ in an urban peripheral area of A bidjan. A ID S C are1993; 5: 187-197.

7. White R, Cleland J and Caraël M . Links between premarital sexual behaviour and extramarital intercourse: a multi-site analysis. A ID S 2000; 14: 2323-2331.

8. Harris JR. The $\mathrm{N}$ urture A ssumption: W hy C hildren turn out theway they do. N ew York: F ree Press, 1998.

9. Scarr S. D evelopmental theories for the 1990's: development and individual difference. Child D ev 1992; 63: 1-19.

10. Scarr S. Biological and cultural diversity: thelegacy of $D$ arwin for development. Child D ev 1993; 64: 1333-1353.

11. Lewis M . A ltering F ate: $W$ hy the $P$ ast does not $P$ redict theF uture. N ew York: G uilford Press, 1997.

12. Brown BB. Lamborn, SL, Mounts NS and Steinberg $L$. Parenting practices and peer group affiliation in adolescence. C hild D ev 1993; 64: 467482.

13. Romer D, Black M, Ricardo I, Feigelman $\mathrm{S}, \mathrm{K}$ alijee $L, G$ albraith J, et al. Social influences on the sexual of youth at risk for HIV exposure. A m J Public H ealth 1994; 84: 977-985.

14. N ada RajaS and Stanton W. Perceived attachment to parents and peers and psychological wellbeing in adolescence.J Y outh A dolesc 1992; 21: 471- 485.

15. Patterson $G R$, Reid JB and D ishion TJ. A Social $L$ earning A pproach: V olume 4. A nti-Social B oys. E ugene, O R: Castalia, 1992.

16. Pryor $J$ and Woodward L. Families and parenting. In: Silva PA and Stanton WR (E ds.). F rom C hild to A dult: The $D$ unedin M ultidisciplinary $H$ ealth and $D$ evelopment Study A uck land. N ew Zealand: O xford University Press; 1996, p. 247-258.

17. Bohman M. Predisposition to criminality: Swedish adoption studies in retrospect. In: Bock
GR and Goode JA (Eds.). G enetics of C riminal and $A$ ntisodal B ehaviour. Chichester: John Wiley, 1996, p. 99-114.

18. K ochanska G. M ultiple pathways to conscience for children with different temperaments. $D$ ev Psychol 1997; 33: 228-240.

19. Wright DW, Peterson LR and Barnes HL. The relation of parental employment and contextual variables with sexual permissiveness and gender role attitudes of rural early adolescents. J E arly A dolesc 1990; 10: 382-398.

20. Louis $\mathrm{H}$ arris and Associates Inc. A merican T eens Speak: Sex, M yths, TV and Birth C ontrol. N ew York: Planned Parenthood Federation of America, 1986.

21. South A frica D epartment of $\mathrm{H}$ ealth. L ovelife sees behavioural changes in teenage sex. http:/ / www.doh.gov.za/ docs/ news/ 2002/ nz0813.html

22. Hutchison $\mathrm{K}$ and Cooney T. Patterns of parentteen sexual risk communication: I mplications for intervention. Fam Re 1998; 47: 185- 194.

23. Kekovole J, K iragu $K, M$ uruli $L$ and Josiah $P$. Reproductive health communication in K enya: Results of a national information, communication, and education situation survey. Johns H opkins U niversity Center for Communication Programs Field Report N 0. 9, Baltimore, MD: Johns H opkins University Center for Communication Programs; 1997.

24. Wilson $D, M$ cmaster J, Armstrong $M$, Magunje $\mathrm{N}$ and Chimhina T. Intergenerational communication within the family: Implications for developing STD / H IV prevention strategies for adolescents in Zimbabwe. Women and AIDS Research Program Research Report No. 13. Washington, D.C.: U nited States Agency for International D evelopment; 1994.

25. Fisher TD. Parent-child communication about sex and young adolescents' sexual knowledge and attitudes. A dolesc 1986; 21: 517-527.

26. Somers CL and Paulson SE. Students' perceptions of parent-adolescent closeness and communication about sexuality: relations with sexual knowledge, attitudes and behaviors. J A dolesc 2000; 23: 629-644.

27. Blake $S M$, Simkin $L$, Ledsky $R$, Perkins $C$ and Calabrese JM. Effects of a parent-child communications intervention on young adolescents' risk for early onset of sexual intercourse. Fam Plan Persp 2001; 33: 52-61.

A frican Journal of Reproductive $\mathrm{H}$ ealth $\mathrm{V}$ ol. $9 \mathrm{~N} 0.1 \mathrm{~A}$ pril 2005 
28. Casper LM. D oes family interaction prevent adolescent pregnancy? Fam Plan Persp 1990; 22: 109-114.

29. Jaccard J, Dittus PJ and G ordon VV. M aternal correlates of adolescent sexual and contraceptive behavior. Fam Plan Persp 1996; 28(4): 159-165, 185.

30. Jaccard J and D ittus P. Parent-adolescent communication about premarital pregnancy. Fam Soc 1993; 74(6): 329-343.

31. Jacobson K C and Crockett LJ. Parental monitoring and adolescent adjustment: An ecological perspective. J R es A dolesc 2000; 10(1): 65-97.

32. Rodgers K B. Parenting processes related to sexual risk-taking behaviors of adolescent males and females. J M arriageF am 1999; 61: 99- 109.

33. M eschke $L L$, Bartholomae $S$ and Zentall MS. Adolescent sexuality and parent-adolescent processes: promoting healthy teen choices. I A dolesc $\mathrm{H}$ ealth 2002; 31: 264-279.

34. Miller $K S, K$ otchick $B A$ and Forehand $R$. A dolescent sexual behavior in two ethnic minority samples: the role of family variables. J $M$ arriage Fam 1999; 61: 85-98.

35. K otchick B, D orsey S, M iller K and Forehand R. A dolescent sexual risk-taking behavior in singleparent ethnic minority families. J Fam P sychol 1999; 13: 93-102.

36. Flewelling $\mathrm{R}$ and Bauman K. Family structure as a predictor of initial substance use and sexual intercoursein earlyadolescence.] M arriageFam 1990; 52: 171-181.

37. K insman $S$, Romer $D, F$ urstenberg $F F$ and Schwarz DF. E arly sexual initiation: the role of peer norms. P ediatrics 1998; 102: 1185-1192.

38. Tambashe BO and Shapiro D. Family background and early life course transitions in K inshasa. J M arriageFam 1996; 58: 1029-1037.

39. Babalola S, Awasum D and Q uenum-Renaud B. The correlates of safe sex practices among
R wandan youth: a positive deviance approach. A fr J A ID S Res 2002; 1: 11-21.

40. Babalola S, Vondrasek C, B rown J and Traore S. The impact of a regional family planning promotion initiative in WestA frica: Evidencefrom Cameroon. Int Fam Plan Persp 2001; 27: 186- 193.

41. Bongaarts J and Watkins SC. Social interactions and contemporary fertility transitions. Pop D ev Rev 1996; 22(4): 639-682.

42. K incaid D L. Social networks, ideation, and contraceptive behavior in Bangladesh: a longitudinal analysis. Soc Sci M ed 2000; 50: 215-231.

43. K incaid D L. Mass media, ideation, and behavior: longitudinal analysis of contraceptive change in the Philippines. C ommun R es 2000; 27: 723- 763.

44. Rosenberg M. Society and the A dolescent Self-I mage. Revised edition. Middletown: Wesleyan U niversity Press, 1989.

45. Begley $\mathrm{CM}$ and White P. I rish nursing students' changing self-esteem and fear of negativeevaluation during their preregistration programme.J A dv N urs 2003; 42: 390-401.

46. Lee $S$ and Lee AM. D isordered eating in three communities of China: a comparative study of female high school students in $\mathrm{H}$ ong $\mathrm{K}$ ong, Shenzhen, and rural H unan. Int J $E$ at D isord 2000; 27: 317-327.

47. Vallières EF and Vallerand RJ. Traduction et validation canadienne-française de l'echelle de I'estime de soi de Rosenberg. J Inter Psychol 1990; 25: 305-316.

48. $\mathrm{K}$ aplan $\mathrm{EL}$ and Meier P. N on-parametric estimation from incomplete observations. J A m Stat A ssoc 1958; 53: 457-481.

49. M otulsky H. IntuitiveStatistics. $\mathrm{N}$ ew Y ork: $\mathrm{O}$ xford University Press, 1995.

50. Cox D. Regression models and life tables. J R oyal Stat Soc Series B 1972; 34: 187-202.

51. Heckman JJ. Sample selection bias as aspecification error. E conometrica 1979; 47: 153-62. 